SOLETRAS

\title{
A teoria e a prática do texto argumentativo em Comunicação em prosa moderna, de Othon M. Garcia
}

André Nemi Conforte ${ }^{1}$

Resumo: Comunicação em prosa moderna, de Othon Moacyr Garcia, cuja primeira edição data de 1967, é considerada obra clássica e de referência entre os estudos textuais no Brasil. Dos diversos aspectos a serem levantados acerca desta obra, chamamos a atenção para a relevância que o autor dá à boa construção de um texto argumentativo - não somente no capítulo a ele dedicado, mas em quase todas as dez partes da obra em estudo, como iremos demonstrar. Nosso intuito, ainda, é o de defender a atualidade e mesmo o pioneirismo, pelo menos em terras brasileiras, de muitas de suas ideias sobre a argumentação. Para tanto, confrontar-se-ão passagens de seu livro e ponto de vistas do autor com obras de alguns nomes de referência para a teoria da Argumentação.

Palavras-chave: Othon Moacyr Garcia. Comunicação em prosa moderna. Argumentação. Texto Argumentativo.

\section{Introdução}

Comunicação em prosa moderna (doravante $\mathrm{Cpm}$ ), de Othon Moacyr Garcia, é considerada, no Brasil, obra de referência no que respeita aos estudos de produção textual, apesar de não constar na bibliografia de boa parte dos livros nacionais de Linguística textual o que se pode explicar, em parte, por ser Cpm um livro menos dedicado à teoria do que a prática do texto. É obra multifacetada, difícil de se classificar, uma vez que tem interessado, ao longo de seus 45 anos de existência, a estudiosos não só de redação, mas também de gramática, de lógica, de metodologia científica e de estilística, para não dizer outros. Ousamos dizer, no entanto, que, pelo menos implicitamente, o objetivo maior da obra (não necessariamente do autor) é fazer com que seu leitor seja capaz, ao fim e ao cabo - se é que, em obra de tal natureza, um "livro de cabeceira", haja fim e haja cabo -, de produzir, sobretudo, um competente texto argumentativo.

\footnotetext{
${ }^{1}$ Possui graduação em Letras (Português-Alemão) pela Universidade do Estado do Rio de Janeiro (2004), mestrado em Letras pela Universidade do Estado do Rio de Janeiro (2007) e doutorado pela Universidade do Estado do Rio de Janeiro (2011). Atualmente é professor adjunto no Instituto de Letras da Universidade do Estado do Rio de Janeiro. É autor de Martinho da Vila: tradição e renovação (Rio Bonito: Almádena, 2011), junto com J. B. M. Vargens. Atua principalmente nos temas: letras de samba, gêneros textuais, metalinguagem, metadiscurso, interdiscurso e intertextualidade, produção textual e crítica literária. E-mail: andreconforte@yahoo.com.br.
} 


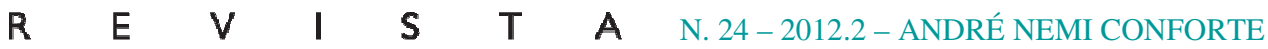

É que acreditamos piamente, após um olhar consideravelmente detido sobre a obra, que Cpm, ao privilegiar a máxima "aprenda a escrever aprendendo a pensar", segundo (nas próprias palavras do autor) os "sãos princípios da lógica", acaba por privilegiar de fato o olhar sobre o modo de organização textual cuja construção e constituição se funda justamente no raciocínio lógico, mais do que o Narrativo e bem mais do que o Descritivo. Tentemos, pois, demonstrá-lo.

\section{Tipologia textual e argumentação}

Dentre os chamados "tipos de texto" (MARCUSCHI, 2005), ou "modos de organização do discurso" (CHARAUDEAU, 2008) ou, ainda, "modos de organização do texto" (OLIVEIRA, 2007), o texto argumentativo tem recebido especial atenção nos estudos linguísticos, principalmente por parte dos teóricos que vinculam os estudos textuais aos discursivos, dada a natural vocação polifônica do modo argumentativo. Nenhum outro tipo de texto é mais sujeito à existência de pressupostos, subentendidos, inferências e outros acontecimentos discursivos que acusam automaticamente a existência de diversas vozes paralelas, do interdiscurso, enfim.

Além disso, parece ser ponto pacífico que, do ponto de vista da estruturação linguística, o modo argumentativo é o que representa um nível mais complexo de elaboração formal, constatação que apresenta resultados de ordem didático-pedagógica evidentes, como o fato de que é esse, em geral, o último modo a ser ensinado nos livros de redação, além de ser o que efetivamente se cobra nas provas de concursos e vestibulares. Lembre-se, ainda, que essa maior elaboração se dá não somente no plano da forma, mas, é claro, também do conteúdo, uma vez que, para se argumentar, pelo menos em nível formal, é necessário que o argumentador tenha desenvolvido a capacidade de realizar encadeamentos lógicos que só uma mente bastante amadurecida pode ter atingido.

Para Charaudeau (2008, p. 201), é mais difícil tratar do modo de organização argumentativo do que do narrativo, "talvez porque o Narrativo, levando em conta as ações humanas, confronta-se com uma forma da realidade, visível e tangível”. O texto argumentativo, ao contrário, "está em contato apenas com um saber que tenta levar em conta a experiência humana, através de certas operações do pensamento" (CHARAUDEAU, 2008, p. 201). Note-se que a distinção feita por Charaudeau difere os dois modos por seu conteúdo, 
$\begin{array}{llllllll}R & \text { E } & \boldsymbol{V} & \mathbf{I} & \mathbf{S} & \mathbf{T} & \mathbf{A} & \text { N. 24-2012.2-ANDRÉ NEMI CONFORTE }\end{array}$

mas não por sua forma, não obstante a complexidade daquele inevitavelmente se relacionar diretamente com a complexidade desta, uma vez que a separação entre uma coisa e outra constitui não mais que um recorte teórico, válido tão somente para fins de análise.

Talvez seja por essa mesma dificuldade do texto argumentativo que "a tradição escolar nunca esteve muito à vontade com essa atividade da linguagem” (CHARAUDEAU, 2008, p. 201): "se as instruções oficiais recomendam que se desenvolvam as capacidades de raciocínio dos alunos, nada é dito sobre o modo de se chegar a isso" (CHARAUDEAU, 2008, p. 201).

Das tantas, porém necessárias, citações do teórico francês da Análise Semiolinguística do Discurso, chama-nos a atenção justamente a última, por entendermos que aí reside a preocupação maior do livro Comunicação em prosa moderna, de Othon Moacyr Garcia (2010): mostrar ao estudante o método pelo qual desenvolverá sua capacidade de raciocínio. E, embora seu autor dedique um capítulo especial à teoria e à prática da argumentação, podese afirmar que todo o livro, como num crescente, oferece subsídios para formular textos argumentativos consistentes. Isto porque a abordagem das estruturas formais da frase, do parágrafo e do texto, aliada ao trabalho com a organização do pensamento, permite que, ao final de sua leitura, torne-se possível ao estudante dominar com segurança os principais modos de organização, mas em especial, assim cremos, o argumentativo. É como se houvesse toda uma cuidadosa, minuciosa e gradual preparação para o grand finale textual do livro.

Ressalve-se que tratar do que chamamos argumentação significa tratar de aspectos muito amplos da linguagem humana, uma vez que parece haver consenso de que a argumentatividade está incrustada em toda a linguagem - embora não se deva, a partir disso, dizer que "todo enunciado é, portanto, argumentativo", pois se trata de uma conclusão falaciosa: uma coisa são os objetivos da comunicação humana, outra é a estrutura linguística e semântica de nossos enunciados, muito embora a própria iconicidade da linguagem tente sempre dar conta de vincular um aspecto ao outro - mas nem sempre consiga.

Não se pode deixar de levar em conta, também, o alargamento semântico do termo argumentação e de seu derivado argumentativo, polissemia possibilitada pela própria natureza da linguagem humana. Portanto, tentaremos deixar claro que, se Cpm se compõe de momentos em que a argumentação é claramente trabalhada, haverá outros, decerto mais numerosos, em que o foco na argumentatividade - sem que o autor empregue esse termo será dado. Isso pode significar, em última análise, que, embora sendo a argumentatividade mais ampla do que a argumentação - vez que aquela se encontra no todo da linguagem 


\section{$\begin{array}{llllllll}R & \text { E } & \boldsymbol{V} & \text { I } & \text { S } & \text { T } & \text { A } & \text { N. 24-2012.2-ANDRÉ NEMI CONFORTE }\end{array}$}

humana -, o foco teórico e didático na primeira pode ser de grande valia para a compreensão e melhor manipulação da segunda.

Após essa longa e talvez desnecessária digressão, vejamos, pois, as partes (ou seja, cada uma das dez subdivisões) de Cpm que serviriam, a nosso ver, como suporte ao desenvolvimento de um eficiente texto argumentativo. Não nos esqueçamos, todavia, de fazer valer aqui também a diferença entre uma teoria da argumentação de um método de argumentação. A apresentação da obra mostrará claramente o momento em que uma coisa ou outra estarão postas em relevo, lembrando, no entanto, que os objetivos da obra em estudo são, no mais das vezes, práticos.

Perpassemos, portanto, os momentos da obra que constituiriam a base para o bom desenvolvimento de um texto argumentativo:

\section{Primeira parte: a frase}

\section{Capítulo I:}

1.0 - Estrutura sintática da frase: principalmente o subcapítulo "Frase, gramaticalidade e inteligibilidade", em que o autor demonstra que "a simples gramaticalidade, o simples fato de algumas palavras se entrosarem segundo a sintaxe de uma língua para tentar comunicação não é condição suficiente para lhes garantir inteligibilidade" (GARCIA, 2010, p. 34). Ou seja, é preciso antes organizar o pensamento; aqui o autor já sinaliza a primazia da lógica sobre a gramática.

1.4.0 - Processos sintáticos: quando demonstra, por exemplo, as implicações pragmáticas de se utilizar ora a coordenação, ora a subordinação na expressão das ideias, além da justaposição e da correlação, com destaque para esta, dada a força retórica do chamado "período tenso".

1.5.0 - Onde também se conjugam a sintaxe e a semântica com a finalidade de melhor expressão das ideias: as noções de período "tenso" e período "frouxo", "prótase" e "apódose" são fundamentais para a concepção formal do texto argumentativo.

\subsection{0 - Como indicar as circunstâncias e outras relações entre as ideias:} subcapítulo de grande importância, por demonstrar minuciosamente o valor semântico dos conectivos e do léxico em geral na expressão das ideias. O uso adequado dos conectivos e das partículas de transição é de fundamental importância, acima de tudo, no modo argumentativo. 


\section{$\begin{array}{llllllll}R & \text { E } & \text { V } & \text { I } & \text { S } & \text { T } & \text { A } & \text { N. 24-2012.2-ANDRÉ NEMI CONFORTE }\end{array}$}

É neste também que se estabelecerá o maior número das chamadas circunstâncias (tempo, oposição, comparação etc.).

\section{Capítulo II:}

2.0 - Feição estilística da frase: os diferentes tipos de arranjo frasal, seus efeitos, defeitos e virtudes.

\section{Segunda parte: o vocabulário \\ Capítulo I}

1.0 - Os sentidos das palavras: em especial, as análises sobre polissemia e contexto, denotação e conotação.

2.0 - Generalização e especificação: o concreto e o abstrato. Para refinamento da expressão e maior acurácia vocabular, já que as escolhas lexicais são elemento fundamental na construção do texto argumentativo.

3.0 - Como enriquecer o vocabulário: pelo que já se disse no tópico anterior.

\section{Terceira parte: o parágrafo}

Fundamental, em sua totalidade, à construção de um texto bem organizado. Para Garcia, o parágrafo é a unidade da composição, o que significa que sua boa estruturação é crucial para a construção do texto.

Quarta, quinta e sexta partes: eficácia e falácias da comunicação, como criar ideias e pondo ordem no caos

O cerne, o miolo do livro, em que o autor desenvolve o mote "aprender a escrever é aprender a pensar", subtítulo de Comunicação em prosa moderna, e ensina a estruturar as ideias de acordo com os princípios da lógica. Daí Garcia retomar conceitos como método (indutivo e dedutivo), silogismo, falácia, sofisma, epiquirema, entimema, petição de princípio, axioma etc. 
$\begin{array}{llllllll}R & \text { E } & \boldsymbol{V} & \text { I } & \text { S } & \text { T } & \text { A } & \text { N. 24-2012.2-ANDRÉ NEMI CONFORTE }\end{array}$

\section{Sétima parte: planejamento}

Em que se trata, finalmente, dos aqui chamados modos de organização do texto: descrição, narração, dissertação e argumentação. Somente no capítulo 4.0 desta parte do livro é que se trabalhará a argumentação propriamente dita, em sua estruturação formal e informal.

\section{Décima parte: exercícios}

Além de muitas páginas de exercícios acerca dos tópicos anteriores, o autor propõe, da página 502 a 511, dezenas de temas para desenvolvimento.

\section{A argumentação e a dissertação}

Lembremos que não era prática da tradição escolar colocar a argumentação, pelo menos diretamente, entre os modos de organização ensinados. Ensinava-se redação por meio da descrição, da narração e da dissertação. Na parte destinada aos modos de organização do texto ("Planejamento" - lembremos também que em momento algum o autor utiliza qualquer nomenclatura específica para categorizá-los - trata-os como formas de composição), Garcia afirma que

[...] nossos compêndios e manuais de língua portuguesa não costumam distinguir a dissertação da argumentação, considerando esta, apenas "momentos" daquela. No entanto, uma e outra têm características próprias. Se a primeira tem como propósito principal expor ou explanar, explicar ou interpretar ideias, a segunda visa, sobretudo, a convencer, persuadir ou influenciar o leitor ou ouvinte. Na dissertação, expressamos o que sabemos ou acreditamos saber a respeito de determinado assunto; externamos nossa opinião sobre o que é ou nos parece ser. Na argumentação, além disso, procuramos principalmente formar a opinião do leitor ou ouvinte, tentando convencê-lo de que a razão está conosco, de que nós é que estamos de posse da verdade (GARCIA, 2010, p. 380).

A distinção proposta por Garcia nos parece a mesma que, modernamente, se faz entre exposição e argumentação, respectivamente. O modo expositivo "costuma predominar em verbetes de enciclopédias, livros didáticos, comunicações em congressos, aulas, conferências etc." (OLIVEIRA, 2007, p. 85), para citar alguns dos gêneros textuais em que se faz presente. Ainda segundo Oliveira, a exposição se caracteriza: 
a) por um predomínio da atitude comunicativa de informar (sobre a de persuadir, por exemplo); b) por asserções a respeito do mundo, isto é, do referente; c) por uma forte presença da razão e da objetividade, resultando numa macroestrutura logicamente concatenada, frequentemente organizada pelo método dedutivo; d) por um alto índice de coesão referencial; e) pelo uso frequente de conectivos; f) pelo predomínio da terceira pessoa sobre as outras duas (GARCIA, 2010, p. 380).

Embora algumas dessas características, como em b), d) e principalmente em e) estejam também presentes na argumentação, fica claro, pelo confronto entre as citações dos dois autores acima, que ambos estão tratando do mesmo modo por nomes diferentes.

Para o termo dissertação, Oliveira $(2004$, p. 183) reserva a categoria de subgênero textual da redação escolar, uma vez que

O termo dissertação (...) é problemático, já que se refere a uma gama excessivamente variada de textos. Além disso, esse termo não tem o mesmo sentido para o professor de Português e para os demais professores. Para aquele, uma dissertação é uma "sequência de opiniões" destinada a persuadir o destinatário da veracidade de uma tese. Para estes, é a exposição de um tema, sem um empenho excessivo de persuadir o leitor; dissertar sobre um item do conteúdo programático, para eles, é discorrer sobre ele. Numa prova, por exemplo, "questão dissertativa" é a que determina a produção de um pequeno texto.

Com efeito, se diferentes professores dão o mesmo nome a textos de natureza linguística diversa, é porque, em verdade, estão a tratar de um gênero (ou subgênero) textual que se realiza em diferentes modos de organização do texto. Eis por que "essa dicotomia levou alguns estudiosos a distinguir dissertação argumentativa de dissertação expositiva" (OLIVEIRA, 2004, p. 183).

\section{A estrutura da argumentação}

Quanto à parte (sétima) relativa ao planejamento dos textos descritivos, narrativos, dissertativos e argumentativos em Cpm, consideramos relevante, por sua importância no todo da obra, apresentar uma visão resumida dos subcapítulos que tratam da construção do texto argumentativo:

Argumentação: o autor estabelece a necessária distinção, segundo ele, entre argumentação e dissertação, conforme já citado anteriormente. 


\section{$\begin{array}{llllllll}R & \text { E } & \text { V } & \text { I } & \text { S } & \text { T } & \text { A } & \text { N. 24-2012.2-ANDRÉ NEMI CONFORTE }\end{array}$}

Condições da argumentação: Garcia defende que "a argumentação deve basear-se nos sãos princípios da lógica”. Este ponto será discutido adiante.

Consistência dos argumentos: Garcia afirma que a argumentação "esteia-se em dois elementos principais: a consistência do raciocínio e a evidência das provas".

Evidência: para Garcia, há cinco tipos mais comuns de evidência: os fatos propriamente ditos, os exemplos, as ilustrações, os dados estatísticos e o testemunho.

Argumentação informal: a distinção proposta entre argumentação informal e argumentação formal é tão original quanto controversa. Até porque o autor dedica duas páginas a mais àquela, e não inclui, nesta, elementos que consideramos fundamentais, como a concordância parcial. É bom ainda lembrar que a argumentação informal está mais ligada à oralidade, embora saibamos que Cpm é uma obra primordialmente dedicada à escrita. No entanto, o próprio autor adverte que, "embora seja mais comum na língua falada - o que talvez justifique a denominação informal - dela nos servimos também com muita frequência na linguagem escrita" (GARCIA, 2010, p. 384). É verdade, contudo, o que Breton (2003, p. 43) afirma, citando Uli Windisch: "a argumentação é principalmente a argumentação cotidiana”, ou seja, a que está menos presa a rigores formais.

Estrutura típica da argumentação informal em língua escrita ou falada: o autor desenvolve o argumento explicitado no parágrafo anterior e apresenta quatro estágios da argumentação. Ao primeiro estágio da argumentação informal ele chamará proposição (declaração, tese, opinião); ao segundo, concordância parcial; ao terceiro, contestação ou refutação, segundo ele, “o 'miolo' desse tipo de argumentação”; o quarto estágio será a conclusão.

Normas ou sugestões para refutar argumentos - em que o autor reproduz dez "normas" sugeridas por Whitaker Penteado (1964, p. 242) para refutar ideias ou argumentos: apresentemo-las:

$1^{\circ}$ - Procure refutar o argumento que lhe pareça mais forte. Comece por ele. $2^{\circ}$ - Procure atacar os pontos fracos da argumentação contrária.

$3^{\circ}$ - Utilize a técnica de "redução às últimas consequências", levando os argumentos contrários ao máximo de sua extensão.

$4^{\mathrm{o}}$ - Veja se o opositor apresentou uma evidência adequada ao argumento empregado.

$5^{\circ}$ - Escolha uma autoridade que tenha dito exatamente o contrário do que afirma o seu opositor.

$6^{\circ}$ - Aceite os fatos, mas demonstre que foram mal empregados.

$7^{\circ}$ - Ataque a fonte na qual se basearam os argumentos do seu opositor. 
$\begin{array}{llllllll}R & \text { E } & \boldsymbol{V} & \text { I } & \text { S } & \text { T } & \text { A } & \text { N. 24-2012.2-ANDRÉ NEMI CONFORTE }\end{array}$

$8^{\circ}$ - Cite outros exemplos semelhantes, que provem exatamente o contrário dos argumentos que lhe são apresentados pelo opositor.

$9^{\circ}$ - Demonstre que a citação feita pelo opositor foi deturpada, com a omissão de palavras ou de toda a sentença que diria o contrário do que quis dizer o opositor.

$10^{\circ}$ - Analise cuidadosamente os argumentos contrários, dissecando-os para revelar as falsidades que contêm.

Estamos convencidos de que tais sugestões, decerto aproveitáveis, pecam, contudo, por certa circularidade. Isto é, não se pode lê-las sem que nelas se perceba um certo ar de tautologia. De fato, já é de se suspeitar que o autor das sugestões tenha arrolado exatamente dez sugestões. Por que não nove, onze? A impressão que temos é a de que o autor de $A$ comunicação humana, obra que parece ter exercido alguma influência sobre $C p m$, desdobrou três ou quatro sugestões até que chegassem a dez. No mais, como uma ligeira restrição ao modo como Garcia estrutura a argumentação informal, de resto, a nosso ver, muito bem esquematizada, fica a pergunta: por que essa mesma estruturação não pode se aplicar também à argumentação formal? Vejamos, então, a seguir, como se arranja esta:

Argumentação formal: segundo o autor, esta "pouco difere, em essência, da informal; até sua estrutura e desenvolvimento podem ser, em parte, os mesmos. Mas a formal exige outros cuidados" (GARCIA, 2010, p. 388).

Proposição: “[...] deve ser, de preferência, afirmativa e suficientemente específica para permitir uma tomada de posição contra ou a favor" (GARCIA, 2010, p. 388).

Análise da proposição: segundo o autor, este estágio, "que não costuma aparecer na argumentação informal, principalmente na língua falada, constitui na formal estágio da maior importância" (GARCIA, 2010, p. 389). Diz respeito ao planejamento sobre o que se proporá na discussão, principalmente em relação ao léxico empregado.

Formulação dos argumentos: constitui a argumentação propriamente dita: "É aí que a coerência do raciocínio mais se impõe" (GARCIA, 2010, p. 389).

Apresentada a estrutura básica da argumentação em Cpm, passemos agora à análise de alguns pontos em particular.

\section{A argumentação e a lógica formal}

Retomando o item Condições da argumentação, acima referido, lembramos o que o autor afirma: "a argumentação deve basear-se nos sãos princípios da lógica” (GARCIA, 2010, 
$\begin{array}{llllllll}\mathbf{R} & \mathbf{E} & \boldsymbol{V} & \mathbf{I} & \mathbf{S} & \mathbf{T} & \mathbf{A} & \text { N. 24-2012.2-ANDRÉ NEMI CONFORTE }\end{array}$

p. 380). (Grifo nosso). Adiante, Garcia sustenta que ela se esteia "em dois elementos principais: a consistência do raciocínio e a evidência das provas" (GARCIA, 2010, p. 381). Tais afirmações, somadas à estrutura geral do livro, em especial a dos capítulos centrais, vinculam a obra de Garcia, e isso nos parece bastante transparente em todo o livro, ao campo da lógica formal.

A vinculação entre uma teoria argumentativa e a lógica formal já era, no entanto, controversa à época: no clássico Tratado de argumentação: a nova retórica, publicado em 1958, Chaïm Perelman e Lucie Olbrechts-Tyteca propunham um novo olhar sobre a técnica da argumentação. Segundo Oliveira (2000, p. 174),

Perelman e Olbrechts-Tyteca já lembram há décadas - a primeira edição do seu Traité de l'argumentation é de 1958 - que a lógica argumentativa tem de substituir pelo conceito de graus de adesão a uma tese o princípio da lógica clássica segundo o qual uma proposição seria ou verdadeira ou falsa, não podendo existir um terceiro valor (princípio do terceiro excluído).

De fato, o princípio do terceiro excluído é fundamental a um raciocínio ligado às ciências exatas, mas não pode se aplicar confortavelmente às humanas. Além disso, uma teoria que buscasse localizar a verdade não em pólos opostos, mas que reconhecesse diferentes graus de adesão à determinada tese traria grandes vantagens, em princípio, aos estudos da argumentação. É esse o ponto de vista que os defensores da "Nova Retórica" (PERELMAN; OLBRECHTS-TYTECA, 2005, p. 10) defendem como forma de diferenciar o seu modus operandi daquele dos lógicos:

Nosso procedimento diferirá radicalmente do procedimento adotado pelos filósofos que se esforçam em reduzir os raciocínios sobre questões sociais, políticas ou filosóficas, inspirando-se em modelos fornecidos pelas ciências dedutivas ou experimentais, e que rejeitam como sem valor tudo o que não se amolda aos esquemas previamente impostos. Muito pelo contrário, nós nos inspiraremos nos lógicos, mas para imitar os métodos que lhes têm propiciado tão bons resultados de um século para cá.

Perelman (1987, p. 234) propõe, portanto, a substituição de um modelo lógico que se mostraria incompatível com os problemas reais:

O desenvolvimento duma teoria da argumentação consiste numa reação contra os esforços dos lógicos modernos, que, na tentativa de renovar a lógica através da análise do raciocínio das matemáticas, identificaram a lógica com a lógica 
formal. Com este procedimento, estes lógicos reduziram de um modo constrangedor conclusões a partir de premissas, graças a regras de inferência previamente formuladas. A demonstração reduz-se assim a um cálculo. A conclusão a que se chega será verdadeira ou simplesmente hipotética em função de as premissas de que se parte serem verdadeiras ou serem admitidas por hipótese. A influência a partir dessas premissas realiza-se em virtude de transformações puramente formais, e as operações lógicas a que se procede são independentes da matéria sobre a qual incide o raciocínio.

O problema dessa aplicação da lógica, ainda segundo o autor belga, é que, "enquanto um sistema dedutivo se apresenta como isolado de todo o contexto, uma argumentação é necessariamente situada" (PERELMAN, 1987, p. 234). Ou ainda, para diferençar ainda mais a argumentação fundamentada em raciocínio silogístico daquela baseada na teoria dos diferentes graus de adesão:

Enquanto a verdade é uma propriedade da proposição, o mesmo não acontece com a adesão: esta é a adesão de um sujeito, de um auditório, e a intensidade de adesão a uma tese constitui uma grandeza variável, constantemente confrontada com a adesão a outras teses: é a razão pela qual a intensidade da adesão poderia sempre ser utilmente acrescida, o que não é o caso quando se trata da verdade de uma proposição (PERELMAN, 1987, p. 234).

Perspectiva semelhante parecem adotar Ducrot \& Anscombre (1988, p. 79), estes adeptos de uma semântica argumentativa que também irá, de modo análogo ao de Perelman \& Olbrechts-Tyteca, abandonar a visão logicizante da linguagem em favor de uma teoria argumentativa que proponha o que chamariam de graus distintos de adesão a uma tese:

Linguistes et philosophes ont toujours été frappés par les possibilités de « raisonnement »- en un sens trés vague du terme - offertes par le langage. Mais ils ont généralement choisi de réduire cette activité de « raisonnement » à la mise en œuvre de relations logiques, i.e., de relations entre valeurs de vérité des énouncés utilisés : incompatibilité, implication... etc. Or si la prise en considération du «raisonnement» nous semble linguistiquement pertinente, sa reduction a la logique (entendue comme système de valeurs de vérité) nous paraît en revanche inacceptable ${ }^{2}$.

\footnotetext{
${ }^{2}$ Linguistas e filósofos sempre se mostraram impressionados com as possibilidades de "racionalização" - num sentido muito vago do termo - oferecidas pela linguagem. Mas, de um modo geral, têm preferido reduzir essa atividade à operacionalização de relações lógicas, isto é, de relações entre os valores de verdade dos enunciados utilizados: incompatibilidade, implicação etc. Ora, se a racionalização da linguagem parece algo linguisticamente pertinente, sua redução à lógica (entendida como um sistema de valores de verdade) parece, no entanto, inaceitável (Nossa tradução).
} 
Seria injusto considerar, no entanto, que o autor de Cpm filia sua teoria argumentativa de modo absoluto ao raciocínio lógico: a própria abundância de exemplificações e de situações reais, cotidianas que Garcia apresenta dá conta do caráter humano, pragmático, de sua teoria argumentativa. Ainda, o fato de ele preconizar, na estruturação da argumentação informal, a elaboração de uma concordância parcial com a tese oposta (como será demonstrado abaixo), já prevê, na possibilidade de uma concessão, um movimento de adesão parcial a determinada tese. Por outro lado, é a própria estruturação geral de CPM (principalmente seus capítulos centrais, como já vimos) que nos leva a concluir que, pelo menos em grande parte, o livro ainda se filia muito mais à lógica do que à chamada retórica.

Se à Retórica coube o papel de abrigar a argumentação, tanto na sua versão mítica (PLANTIN, 1996a apud MARQUES, 2011, p. 270) quanto na Retórica de Aristóteles, o fato é que o espaço por ela conquistado "se foi progressivamente perdendo, nomeadamente, pela sobreposição da lógica e pela redução da retórica a uma arte de bem dizer", nas palavras de Maria Aldina Marques (2011, p. 272-273):

Efetivamente, a lógica favorece esta descontextualização, porque a dedução da verdade a partir de premissas/axiomas não necessita da aceitação do interlocutor. E, em acréscimo, o desenvolvimento da retórica vai, progressivamente, descontextualizar a palavra e tornar-se a arte da ornamentação (MARQUES, 2011, p. 273).

Como sabemos, foi esse o modelo adotado pelo ensino escolástico da Idade Média, e, segundo já afirmamos acima, o retorno à Retórica só se daria, pelo menos simbolicamente, com a publicação da obra clássica de Perelman \& Tyteca. Ressalta a autora, no entanto, que "algumas das novas teorias retóricas da argumentação pretendem reanalisar e redefinir" a relação entre argumentação e lógica "a partir de uma lógica 'informal' ou 'natural' (MARQUES, 2011, p. 273), e não da lógica formal, uma vez que esta, “operando num quadro abstrato, não é adequada nomeadamente à análise da relevância e pertinência de um argumento em função da conclusão pretendida" (MARQUES, 2011, p. 273).

De qualquer forma, autores como Velasco $(2010)$ e Krause $\left(1985^{3}\right.$; 2000) continuam apostando no ensino do pensamento lógico para a boa construção do texto argumentativo, e um autor como Toulmin, que publicou o seu Usos do argumento, um clássico da

\footnotetext{
${ }^{3}$ Este foi relançado em 2010 pela editora Rocco, praticamente sem modificações, o que depõe a favor de sua atualidade.
} 


\section{$\begin{array}{llllllll}\mathbf{R} & \mathbf{E} & \mathbf{V} & \mathbf{I} & \mathbf{S} & \mathbf{T} & \mathbf{A} & \text { N. 24-2012.2-ANDRÉ NEMI CONFORTE }\end{array}$}

argumentação fundamentado na lógica, no mesmo ano (1958) do já citado Tratado de argumentação, continua sendo referência para este campo de estudo; além disso, o livro de Toulmin não é uma exposição acrítica dos fundamentos da lógica aplicados à teoria da argumentação; antes pelo contrário. O próprio autor admite: "o grande fator deturpante (como nós vimos) do desenvolvimento da teoria lógica até aqui tem sido a prática de tratar argumentos num campo como se fornecessem um padrão universal de mérito e validade" (TOULMIN, 2001, p. 364). E sua proposta de aplicação da lógica à teoria da argumentação tenta, de modo bem claro, delimitar o espaço de uma e de outra, como o autor demonstra tanto na introdução quanto na conclusão de sua obra:

Questão central para nós será saber até que ponto a lógica pode esperar ser uma ciência formal e, ainda assim, conservar a possibilidade de ser aplicada na avaliação crítica de argumentos que efetivamente usamos ou que podem ser usados por nós (TOULMIN, 2001, p. 3).

Aqueles com espírito matemático podem, se quiserem, elaborar outros esquemas formais abstratos - padrões de possíveis argumentos separados da verdadeira atividade de argumentar em algum campo conhecido. Mas devem tomar cuidado em atribuir os resultados a alguma das ciências existentes, a menos que estejam preparados para fazer aquilo que vimos que tem de ser feito aqui - esquadrinhar a história lógica, a estrutura e o modus operandi das ciências usando o olho de um naturalista, sem preconceitos ou ideias preconcebidas importadas de fora (TOULMIN, 2001, p. 368-369).

\section{A concordância parcial e a concessão}

Um ponto importantíssimo na estruturação da argumentação informal em Comunicação em prosa moderna está no segundo estágio de 4.3.1, quando o autor discorre sobre a chamada concordância parcial. Reproduzamos o trecho parcialmente:

Na concordância parcial (não sabemos que outro nome dar ao segundo estágio deste tipo de argumentação informal), o autor, ou falante, reconhece que em certos casos, excepcionais, é possível que a pancada eduque, seja um bom corretivo, mas - frise-se bem - só em certos casos, só em certa medida, só em condições muito especiais e, assim mesmo, em poções medicamentosas, homeopáticas...

A concordância parcial (fique a denominação) reflete uma atitude natural do espírito em face de certas ideias ou teses, pois é incontestável que existem quase sempre "os dois lados da medalha"; muitas ideias admitem concordância parcial ou contestação parcial: basta encará-las do ponto de vista geral ou do ponto de vista particular, basta atentar em certas circunstancias, em certos fatores (GARCIA, 2010, p. 385). (Grifos nossos). 
Os trechos por nós destacados se prestam a demonstrar que Garcia já intuía - na verdade, verificava - a existência desse momento em que mais se mostra a natureza polifônica, dialógica da argumentação. Por falta de outro nome, chamou-o concordância parcial. Em seguida, apresenta o terceiro estágio, denominado contestação ou refutação. Porém, no último parágrafo do segundo estágio faz a seguinte advertência: "entretanto, pode não haver, ou é possível que não encontremos, razões para uma concordância parcial; então, passamos diretamente da proposição à contestação [...]”' (GARCIA, 2010, p. 385).

Vejamos como se caracteriza o terceiro estágio:

Aqui também a forma verbal assume feição típica; quase sempre - já que se trata de opor aos argumentos favoráveis precedentes, ou à proposição toda, outros, contrários - o período ou parágrafo, ou o trecho da fala na língua oral, que lhe correspondam, se iniciam com uma conjunção adversativa ou expressão equivalente:

"Mas, por outro lado..."

"Entretanto, na maioria dos casos... a pancada não educa, é um método de educação, condenável, porque..."

Seguem-se então a essa frase inicial da contestação as razões expressas em orações encabeçadas geralmente por conjunções explicativas ou causais:

“... porque humilha, revolta, cria complexos...” (GARCIA, 2010, p. 386)

Por fim, resume Garcia:

Em conjunto, esses dois estágios expressam um pensamento essencialmente concessivo, resultante do enlace semântico entre os enunciados introduzidos, respectivamente, por "é verdade", "é certo", e por uma oração adversativa. É evidente que a ideia de concessão - que se filia à de oposição e de ausência de condição - advém da presença da oração adversativa, tendo "é verdade que", "é certo que"... a função, primeiro, de indicar em que termos ou extensão se concorda com o que está declarado antes, e, segundo, de preparar o espírito do leitor, ou ouvinte, para a restrição (contestação, discordância, objeção parcial), que se vai enunciar a seguir (a partir da oração adversativa) (GARCIA, 2010, p. 386). (Negritos nossos).

Charaudeau incluirá o que ele chama de restrição entre os modos de encadeamento da argumentação: "sabe-se que essa operação se baseia numa relação de causa e consequência cuja conclusão esperada é anulada e substituída por uma asserção contrária: "Ele é inteligente [portanto poder-se-ia esperar que compreendesse], entretanto não compreende essas coisas" (CHARAUDEAU, 2008, p. 210-211). Mais adiante, o autor francês arrola a concessão 
restritiva entre os modos de raciocínio, este se inscrevendo numa forma de raciocínio dedutivo:

[...] consiste em aceitar A1 [asserção de partida], em colocá-la como verdadeira (fazer uma concessão), e, ao mesmo tempo, retificar a relação argumentativa. Aceita-se a asserção de partida, mas contesta-se que ela possa levar à conclusão proposta ou subentendida (CHARAUDEAU, 2008, p. 218).

Ducrot (1987, p. 216) também se refere ao chamado "ato de concessão": "ele consiste em fazer ouvir um enunciador argumentando no sentido oposto ao seu, enunciador do qual se distancia" [...] "todo mundo sabe que a concessão é, entre as estratégias de persuasão, uma das mais eficazes, essencial em todo caso, ao comportamento dito 'liberal"'.

Jean-Michel Adam, por sua vez, faz uso do termo restrição, a partir de um exemplo como La marquise a les mains douces, mas je ne l'aime pas, para o qual apresenta o seguinte esquema, que demonstra relativa convergência com as demais teorias da argumentação, inclusive com as ideias de Othon Moacyr Garcia:

Proposition $\mathrm{p}$

[La marquise a les mains douces] -RÉGLEdonc probablement-

D'INFÉRENCE

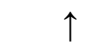

puisque

GARANT

[Les hommes aiment

les femmes qui ont

les mains douces] $\rightarrow$ [J'aime la marquise $]$

CONCLUSION

\section{Conclusão}

Parece-nos bastante razoável defender, a partir do exposto acima, que a contribuição de Comunicação em prosa moderna aos estudos da argumentação é bastante relevante, dados o pioneirismo e a atualidade de muitos de seus ensinamentos práticos. Se o autor carecia ainda das ferramentas que a Análise do Discurso, com suas subdivisões e áreas de entorno, veio disponibilizar aos estudiosos, não lhe faltaram os insights suficientes para perceber que uma abordagem da argumentação necessariamente filiada à lógica não significava uma abordagem estritamente formal da linguagem, que negligenciasse as tantas nuances que a atividade linguageira, para dizer um termo mais corrente, nos apresenta. 
$\begin{array}{llllllll}\mathbf{R} & \mathbf{E} & \boldsymbol{V} & \mathbf{I} & \mathbf{S} & \mathbf{T} & \mathbf{A} & \text { N. 24-2012.2-ANDRÉ NEMI CONFORTE }\end{array}$

Dá-nos essa conclusão, portanto, estofo suficiente para afirmar que a obra capital de Othon Moacyr Garcia merece continuar sendo estudada e avaliada, por seu pioneirismo e por sua atualidade verificados por tantos quanto se detenham sobre suas mais de quinhentas páginas.

\section{Referências bibliográficas:}

ADAM, Jean-Michel. Les textes: types et prototypes. 4. ed. Paris : Editions Nathan, 1992.

BRETON, Philippe. A argumentação na comunicação. 2. ed. Bauru, SP: Edusc, 2003.

CHARAUDEAU, Patrick. Linguagem e discurso: modos de organização. São Paulo: Contexto, 2008.

GARCIA, Othon M. Comunicação em prosa moderna. 27. ed. Rio de Janeiro: Ed. da FGV, 2010.

KRAUSE, Gustavo Bernardo Galvão. Redação inquieta. Rio de Janeiro: Globo, 1985.

. Educação pelo argumento. Rio de Janeiro: Rocco, 2000.

MARQUES, Maria Aldina. Argumentação e $(m)$ discursos. In: DUARTE, Isabel Margarida; FIGUEIREDO, Olívia (Orgs.). Português, linguagem e ensino. Porto: Universidade do Porto Editorial, 2011.

OLIVEIRA, Helenio Fonseca de. Categorias do modo argumentativo de organização do discurso e relatores. In: GÄRTNER, E. et al. (Eds.). Estudos de linguística textual do português. Frankfurt: TFM, 2000.

Gêneros textuais e conceitos afins: teoria. In: VALENTE, André (Org.). Língua portuguesa e identidade: marcas culturais. Rio de Janeiro: Caetés, 2007.

PENTEADO, J. R. Whitaker. A técnica da comunicação humana. 6. ed. São Paulo: Pioneira, 1977.

PERELMAN, Chaïm. Verbete Argumentação. Enciclopédia Einaudi, v. 11. Oral/Escrito/Argumentação. Imprensa Nacional; Casa da Moeda. Edição Portuguesa, 1987.

PERELMAN, Chaïm; OLBRECHTS-TYTECA, Lucie. Tratado da argumentação: a nova retórica. São Paulo: Martins Fontes, 2005.

TOULMIN, Stephen. Os usos do argumento. São Paulo: Martins Fontes, 2001.

VELASCO, Patrícia del Nero. Educando para a argumentação: contribuições do ensino da lógica. Belo Horizonte: Autêntica, 2010. 


\title{
Theory and practice of the argumentative text in the work Comunicação em prosa
} moderna, by Othon M. Garcia

\begin{abstract}
Othon Moacyr Garcia's Comunicação em prosa moderna, whose first edition dates back to 1967, is considered a classical reference as regards to textual studies in Brazil. Of the many issues to be raised about this book, we call attention to the relevance its author gives to the good writing of an argumentative text - not only in the chapter dedicated to it, but in almost all ten parts of the work under study, as we shall try to show. Our intention is also to defend the up-to-date and pioneer aspects, at least in Brazil, of many of his ideas about argumentation. In order to achieve these aims, passages of Garcia's book and Garcia's points of view will be confronted with some seminal works about the theory of Argumentation.
\end{abstract}

Key words: Othon Moacyr Garcia. Communication in modern prose. Argumentation. Argumentative text.

Recebido em: 15 de dezembro de 2012.

Aprovado em: 05 de janeiro de 2013. 